\title{
Comparison of Two Differently Processed Acellular Dermal Matrix Products for Root Coverage Procedures: A Prospective, Randomized Multicenter Study
}

Hom-Lay Wang, ${ }^{*}$ Georgios E. Romanos, ${ }^{\dagger}$ Nicolaas C. Geurs, ${ }^{\dagger}$ Andrew Sullivan, $\S$ Fernando Suárez-López del Amo, ${ }^{*}$ and Robert M. Eber*

Background: The purpose of this multicenter randomly controlled clinical trial was to compare two acellular dermal matrix (ADM) materials produced by different processing techniques, freeze-dried (FDADM) and solvent-dehydrated (SDADM) ADM, in their ability to correct Miller Class I and II recession defects.

Methods: Eighty individuals from four study centers, each with a single maxillary anterior Miller Class I or II recession defect were enrolled. Participants were randomly assigned and treated with coronally advanced flap $(C A F)+\operatorname{FDADM}(n=42)$ or CAF + SDADM $(n=38)$. Gingival thickness, recession depth, recession width, probing depth (PD), clinical attachment level, gingival index, plaque index, patient discomfort, and wound healing index were recorded before surgery (day 0), immediately after surgery (day 1 ), and 2, 4, 12, 24, and 52 weeks postoperatively. The Student $t$ test, paired $t$ test, and Kruskal-Wallis one-way ANOVA were used to analyze the data.

Results: When evaluating the clinical parameters after 1 year, both groups showed significant $(P<0.05)$ improvement for most of the parameters evaluated when compared to baseline (day 0$)$. For example, percentage of root coverage was $77.21 \% \pm 29.10 \%$ for CAF + FDADM and $71.01 \% \pm 32.87 \%$ for CAF + SDADM. Conversely, no significant differences were observed between the two materials for any clinical parameter tested or for patient satisfaction except PD on the mesial side of the defects $(P=0.03)$.

Conclusions: Both FDADM and SDADM can be used successfully to correct Miller Class I or II recession defects. There were no statistically significant differences between groups for any of the clinical parameters tested. J Periodontol 2014;85:1693-1701.

\section{KEY WORDS}

Acellular dermis; dental; esthetics; gingival recession; surgery, plastic; treatment outcome.

\footnotetext{
* Department of Periodontics and Oral Medicine, University of Michigan School of Dentistry, Ann Arbor, MI.

$\dagger$ Department of Periodontics, Stony Brook School of Dental Medicine, Stony Brook, NY.

\# Department of Periodontics, University of Alabama at Birmingham School of Dentistry, Birmingham, AL.

$\S$ Department of Periodontics, Rutgers, The State University of New Jersey, School of Medicine and Dentistry, Newark, NJ.
} 
I $\mathrm{t}$ is estimated that 23.8 million people $(22.5 \%)$ in the United States, aged $>29$ years, have gingival recession (GR). ${ }^{1}$ The prevalence, extent, and severity of GR increases with age. ${ }^{2} \mathrm{GR}$ is more prevalent and severe at the facial surfaces of teeth. ${ }^{1}$ Thus, GR is common in the United States adult population, and appropriate measures to prevent or control this condition are desirable. ${ }^{1}$

Coronally advanced flaps (CAFs) and combinations of CAFs and other tissue grafts, such as subepithelial connective tissue (CT), acellular dermal matrix (ADM), etc., all can be used to successfully treat GR. ${ }^{3-5} \mathrm{CAF}$ combined with subepithelial CT autograft has been the gold standard for treating recession; however, the morbidity associated with harvesting donor tissue from a second surgical site led clinicians to seek other, less invasive alternatives. To meet this challenge, ADM was developed and has shown promising results., ${ }^{4,6-9}$ Two major types of ADM products are commercially available: 1) freeze-dried (FDADM), $\|$ and 2) solventdehydrated (SDADM)." In both processes, epidermis and the cellular elements of dermis are removed to provide a material consisting primarily of fibrillar collagen mesh and elastin. According to the manufacturer, processing of FDADM begins with removal of the epidermis using a buffered salt solution. Multiple cell types within the dermis are then dissolved and washed away using a non-denaturing detergent that rapidly diffuses into the dermis. Finally, after a cryopreservant is added to avoid damaging crystal formations, the processed tissue matrix is freeze dried. For SDADM, according to the manufacturer, the sterilization process $^{\#}$ gently removes unwanted materials, such as cells, antigens, and viruses, and inactivated any pathogens. ${ }^{10}$ The steps in processing include osmotic, oxidative, and alkaline treatment, solvent dehydration, and limited-dose gamma irradiation for sterilization. During solvent dehydration, the tissue is placed several times in different gradations of acetone. At the end of this step, acetone is left to evaporate in a vacuum chamber. This results in dry tissue with residual water content of $<5 \%$ that can be stored at room temperature. When used as a graft, ADM acts as a scaffold for new tissue growth. Although ADM was used successfully to treat recession defects, there has been only one direct comparison of FDADM and SDADM for the treatment of human GR defects reported in the literature. ${ }^{11}$

The purpose of this study is to evaluate whether clinical parameters were improved by SDADM when compared to FDADM for the treatment of Miller Class I or II GR ${ }^{12}$ defects in a multicenter controlled, randomized clinical trial (RCT).

\section{MATERIALS AND METHODS}

The study population consisted of patients with one Miller Class I or II facial GR defect, $\geq 2 \mathrm{~mm}$, located on the facial aspect of a maxillary incisor, canine, or premolar from four centers: 1) Center 3515: University of Michigan School of Dentistry; 2) Center 3507, Eastman Institute for Oral Health, University of Rochester, New York; 3) Center 3514: University of Alabama at Birmingham School of Dentistry; and 4) Center 3508: Rutgers, The State University of New Jersey. The Western Institutional Review Board (IRB) and each center's IRB approved this project, and the study was conducted in accordance with the Helsinki Declaration of 1975 as revised in 2000. All participants gave written and verbal consent to participate. A power analysis was conducted to determine the sample size based on testing the difference of GR reduction from baseline to 1 year between FDADM treatment and SDADM treatment. Assuming there is no root coverage status changes from 6 months to 1 year after surgery, according to Novaes et al. (2001), ${ }^{13}$ it was estimated the two treatment groups have a common standard deviation (SD) of $1 \mathrm{~mm}$. The sample size ratio of the two groups was set as 1:1. It was determined that a sample size of 34 per group would provide $80 \%$ power to detect $0.7-\mathrm{mm}$ difference between the group means at a type I error rate of 0.05 using a two-sided Student $t$ test. Based on the power-size calculation, from November 2009 to December 2010, a total of 80 individuals (26 males and 54 females, aged 23 to 74 years; mean age: 45.3 years) were enrolled in this prospective RCT in four study centers. This multicenter RCT is registered at clinicaltrials.gov as NCT00881959.

Participants were aged $\geq 18$ years, able to understand and comply with all instructions, and able to maintain good oral hygiene (O'Leary plaque score $\leq 20 \%) .{ }^{14}$ Exclusion criteria included: 1) previous surgery in the study area within the past 12 months; 2) antibiotic use exceeding 2 weeks duration within the past 3 months; 3 ) allergy to any of the study materials; 4) concomitant use of medications known to cause gingival enlargement; 5) use of systemic steroids; 6) unstable systemic diseases; 7) compromised immune function; 8) active infection; and 9) tobacco use within the past year. In addition, females who were pregnant or attempting to become pregnant were excluded.

Participants were assigned randomly to one of two treatment groups on the day of surgery: 1) CAF + SDADM, or 2) CAF + FDADM. A third party (a sponsor) $* *$ provided a box containing 20 sequential randomization cards for each center in sealed envelopes. The FDADM group included 42 participants, and the SDADM group included 38 participants, with the non-significant difference being attributed to

\| Alloderm, BioHorizons, Birmingham, AL.

If Puros Dermis, Zimmer Dental, Carlsbad, CA.

\# Tutoplast process, Zimmer Dental.

** Zimmer Dental. 
randomization. All centers enrolled 20 patients, and they are equally divided into 10 patients for each group, except Center 3508, which had eight patients in the SDADM group and 12 patients in the FDADM group. The FDADM group had 26 (61.9\%) females and $16(38.1 \%)$ males, whereas the SDADM group had 28 (73.7\%) females and 10 (26.3\%) males. Immediately before surgery, the surgeon drew an envelope from the box and opened it to reveal the treatment group for the patient. Randomization was performed before surgery because the rehydration process for the test and control ADM materials had to be initiated before the surgical procedure started. Rehydration of ADM materials was performed according to the manufacturers' instructions. SDADM was hydrated for 5 to 30 minutes in endotoxin-free, room-temperature $0.9 \%$ sterile saline. FDADM was hydrated in two separate saline baths, 10 minutes each, for a total of 20 minutes.

All surgeries were performed as described previously ${ }^{15}$ using CAF, periosteal release and blunt dissection for tension-free closure, and the sling-andtag suturing technique. Surgeons (H-LW, GER, AS, NCG, RME) from each center measured recession depth (RD) (X) with a periodontal probe ${ }^{\dagger \dagger}$ and then used the same probe to create a bleeding point apical to each adjacent gingival papilla at a distance equal to the RD plus $1 \mathrm{~mm}(X+1)$. Starting at the level of the bleeding points, diverging vertical incisions were made at mesio-facial and disto-facial line angles of the study tooth. After connecting the vertical incisions with a sulcular incision, a full-thickness mucoperiosteal flap was elevated several millimeters beyond the mucogingival junction. An interproximal

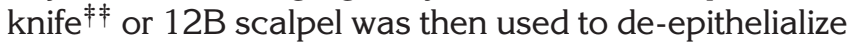
adjacent gingival papillae. The exposed root was planed with curets, and any tissue tags were removed from the flap and adjacent papillae with curved iris scissors. Next, the periosteum was scored near the base of the flap, and submucosal tissues were undermined via blunt dissection with a pair of scissors to allow coronal positioning of the flap without tension, in the following manner: while grasping the flap with tissue forceps and applying gentle traction in a coronal and lateral direction, the surgeon made a shallow horizontal incision through the periosteum on the internal aspect of the flap, at a level several millimeters apical to the vestibule. Curved scissors $\S \S$ were inserted, with the tips closed, into the incision in an apico-lateral direction, paralleling and undermining the vestibular fold, and then were opened gently to bluntly separate the submucosal CTs and muscle fibers. This procedure was repeated until the flap could be pulled coronally without tension to a level that, in most cases, approximated the incisal edge or facial cusp tip of the tooth. The surgeon then trimmed the rehydrated ADM (SDADM or FDADM, depending on randomization) so that it was trapezoidal in shape, extended at least $3 \mathrm{~mm}$ lateral and apical to the exposed root surface when positioned at the cemento-enamel junction (CEJ), and came no closer than $1 \mathrm{~mm}$ to the vertical incisions outlining the recipient bed. The ADM graft was secured to the test tooth at the level of the CEJ with a single-sling, 5-0, fast-absorbing polyglycolic-acid suture.|l| The tissue flap was then advanced to a level 1 to $2 \mathrm{~mm}$ coronal to the CEJ so that the ADM was completely covered, and the flap was secured with the sling-and-tag suture technique with 5-0 polyglycolic-acid sutures as described previously. ${ }^{15}$

At the time of surgery, each surgeon completed a questionnaire regarding the handling characteristics of the ADM grafting material used. Postoperative medications included $600 \mathrm{mg}$ ibuprofen every 6 to 8 hours as needed and $500 \mathrm{mg}$ amoxicillin three times daily for 10 days, starting 1 hour before surgery. Patients were given $500 \mathrm{mg}$ azithromycin 1 hour before surgery and then $250 \mathrm{mg} / \mathrm{d}$ for 5 days if they were allergic to amoxicillin. After surgery, patients were instructed to rinse with warm salt water twice daily, not to brush or floss the area until after the 14day postoperative visit or until the surgeon instructed them to do so, restrict physical activity for 1 week, and to eat a soft diet. Postoperative visits were scheduled at $14 \pm 3,30 \pm 7,90 \pm 7,180 \pm 14$, and $365 \pm 14$ days. At the 14-day visit, the surgeon removed some or all external sutures as he/she deemed appropriate. At each postoperative visit, oral hygiene instructions and professional cleaning were provided if plaque accumulation was noted at the study site.

One calibrated, trained, masked examiner in each center (Mary Layher, RDH, University of Michigan, Ann Arbor, MI; Mary Therese Keating-Biltucci, RDH, University of Rochester, Stony Brook, NY; Philip Vassilopoulos, DDS, University of Alabama at Birmingham School of Dentistry, Birmingham, AL; Karen J. Pyra, RDH, Rutgers, The State University of New Jersey, School of Medicine, Newark, NJ) measured and recorded all clinical parameters. Examiners' calibration revealed $\geq 70 \%$ interexaminer agreement $( \pm 1 \mathrm{~mm})$ and $\geq 90 \%$ intraexaminer agreement $( \pm 1 \mathrm{~mm})$

Custom acrylic guides were fabricated to align probing depth (PD), GR, and gingival thickness (GT) measurements at the mid-facial aspect of the test teeth. Plaque index, ${ }^{16}$ and gingival index ${ }^{17}$ were recorded before surgery and at each postoperative

\footnotetext{
$\dagger \dagger$ UNC-15 periodontal probe, Hu-Friedy, Chicago, IL.

玤 Orban interproximal knife, Hu-Friedy.

$\S \S$ Metzenbaum scissors, Hu-Friedy.

IIII Polyglycolic acid sutures, Ace Surgical Supply, Brockton, MA.
} 
visit. Wound healing index ${ }^{18}$ and patient discomfort level $(1=$ mild, 2 = mild to moderate, $3=$ moderate, $4=$ moderate to severe, $5=$ severe) were recorded at each postoperative visit. RD and recession width (RW) were recorded before surgery, after suturing, and at each postoperative visit. Percentage of root coverage was a mathematic calculation taken directly from the mid-facial measurement before treatment versus after treatment. PD, clinical attachment level (CAL, equal to PD + RD), and GT were measured at baseline (before surgery) and at the 90-, 180-, and 365-day visits. After applying a topical anesthetic, GT was measured mid-facially, 1 and $3 \mathrm{~mm}$ apical to the gingival margin, by penetrating the soft tissue with an endodontic broach that had an attached rubber stopper. GT measurements were then calculated to the nearest $0.5 \mathrm{~mm}$ using a metal ruler. All other clinical measurements were made using a calibrated periodontal probe. To assess patient satisfaction, patients filled out a patient quality assessment form at the 180- and 365-day visits.

Demographic information, baseline information, and outcome clinical parameter follow-up assessments were summarized by the descriptive statistics chosen appropriate to the data scale. Continuous data were summarized by mean, SD, sample size (n), minimum, and maximum. Categoric data were summarized by frequency and percentage. Student $t$ test was used to compare the primary clinical outcome parameters between FDADM treatment and SDADM treatment. Paired $t$ test was used to evaluate the primary clinical outcome parameter improvement from baseline to 1 year within each treatment group. Kruskal-Wallis one-way ANOVA was applied to examine the variations of the primary clinical outcome parameters caused by the different clinical centers. Post hoc pairwise comparisons with $P$ values adjusted for family-error rate were provided to identify the particular significant difference between the different centers.

\section{RESULTS}

Mean age was $47.4 \pm 14.0$ and $43.0 \pm 13.0$ years for FDADM and SDADM, respectively. There was no statistically significant difference in the distribution of Miller Class defects between groups, the majority being Miller Class I. In addition, approximately half of the teeth treated in each group were maxillary canines. Most of the patients in both groups showed good to excellent oral hygiene throughout the study. Table 1 presents the enrolled participants' demographic information and defect characteristics. Figures 1 and 2 illustrate a patient treated with each processed membrane.

With regard to adverse events, only minimal complications were reported during the study period.
Only one patient in each group reported graft exposure and infection. Interestingly, one patient in the SDADM group reported paresthesia after surgery; however, it was resolved during the follow-up period.

When evaluating the clinical parameters after 1 year, significant differences were found within groups for most of the parameters evaluated (Table 2). Both groups had significant $(P<0.05)$ RD reduction $(2.00 \pm$ $0.87 \mathrm{~mm}$ for FDADM and $2.06 \pm 1.11 \mathrm{~mm}$ for SDADM) and percentage of root coverage $(77.21 \% \pm$ $29.10 \%$ and $71.01 \% \pm 32.87 \%$ for FDADM and SDADM, respectively; $P<0.0001$ ) when compared to baseline. Both groups showed a significant increase in CAL $(P<0.0001)$, with $-1.69 \pm 1.08$ and $-1.57 \pm$ $1.19 \mathrm{~mm}$ for FDADM and SDADM, respectively.

Conversely, no significant differences were observed between the two treatment groups except PDs on the mesial side of the defects $(P=0.03)$, with $2.63 \pm 0.63$ and $2.33 \pm 0.57 \mathrm{~mm}$ for FDADM and SDADM, respectively. Although statistically significant, the clinical significance of this $0.3-\mathrm{mm}$ difference could

Table I.

\section{Demographic Information of the Study}

\begin{tabular}{|c|c|c|}
\hline Variable & FDAMD $(n=42)$ & $\operatorname{SDAMD}(n=38)$ \\
\hline \multicolumn{3}{|l|}{ Sex } \\
\hline Males & $38.1 \%(16)$ & $26.3 \%(10)$ \\
\hline Females & $61.9 \%(26)$ & $73.7 \%(28)$ \\
\hline Age (years) (mean $\pm \mathrm{SD})$ & $47.4 \pm 14.0$ & $43.0 \pm 13.0$ \\
\hline \multicolumn{3}{|l|}{ Miller's Class } \\
\hline | & $88.1 \%(37)$ & $84.2 \%(32)$ \\
\hline$\|$ & $11.9 \%(5)$ & $15.8 \%(6)$ \\
\hline \multicolumn{3}{|l|}{ Oral hygiene level } \\
\hline Excellent & $40.5 \%(17)$ & $55.3 \%(21)$ \\
\hline Fair & $2.4 \%(1)$ & \\
\hline Good & $57.1 \%(24)$ & $44.7 \%(17)$ \\
\hline \multicolumn{3}{|l|}{ Race } \\
\hline African American & $4.8 \%(2)$ & \\
\hline Asian & $2.4 \%(1)$ & $5.3 \%(2)$ \\
\hline White & $73.8 \%(31)$ & $84.2 \%(32)$ \\
\hline Hispanic & $11.9 \%(5)$ & $7.9 \%(3)$ \\
\hline Other & $7.1 \%(3)$ & $2.6 \%(1)$ \\
\hline \multicolumn{3}{|l|}{ Tooth \# } \\
\hline 4 & & $7.9 \%(3)$ \\
\hline 5 & $19.0 \%(8)$ & $23.7 \%(9)$ \\
\hline 6 & $33.3 \%(14)$ & $18.4 \%(7)$ \\
\hline 7 & $2.4 \%(1)$ & $2.6 \%(1)$ \\
\hline 8 & $4.8 \%(2)$ & \\
\hline 9 & & $5.3 \%(2)$ \\
\hline 10 & $2.4 \%(1)$ & \\
\hline 11 & 19.0\% (8) & $31.6 \%(12)$ \\
\hline 12 & $19.0 \%(8)$ & $10.5 \%(4)$ \\
\hline
\end{tabular}



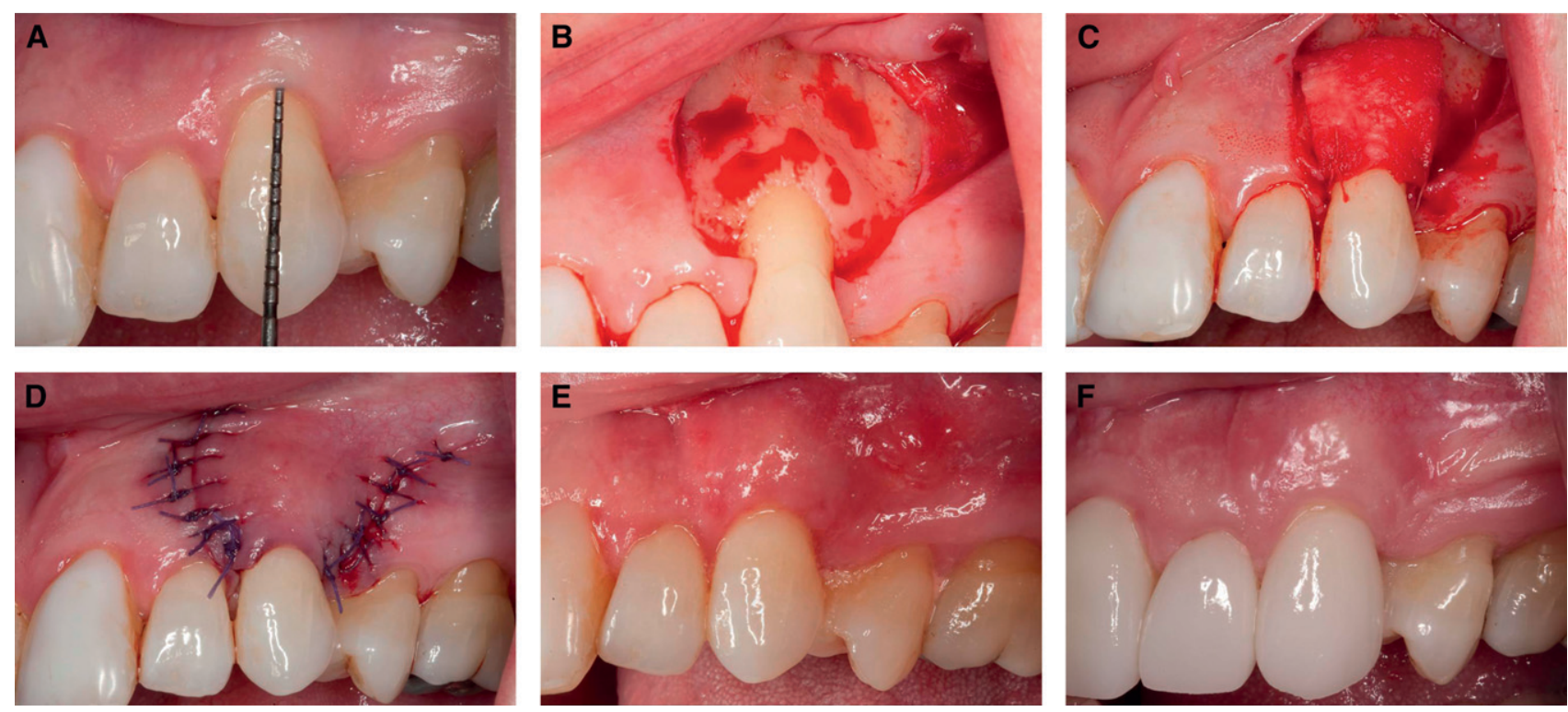

Figure I.

A patient treated with SDADM. A) Tooth \# I I presents 3-mm Miller's Class I facial GR. B) The flap was reflected using a full-thickness flap with two divergent vertical releasing incisions. C) SDADM was trimmed to cover $3 \mathrm{~mm}$ beyond the recession defect and then secured with single-sling sutures. D) The flap was coronally advanced following the sling-and-tag suturing technique. ${ }^{15}$ E) Four weeks after surgery, there was good soft-tissue healing and recession defect coverage. F) Twelve months after surgery, there was 100\% recession defect coverage.
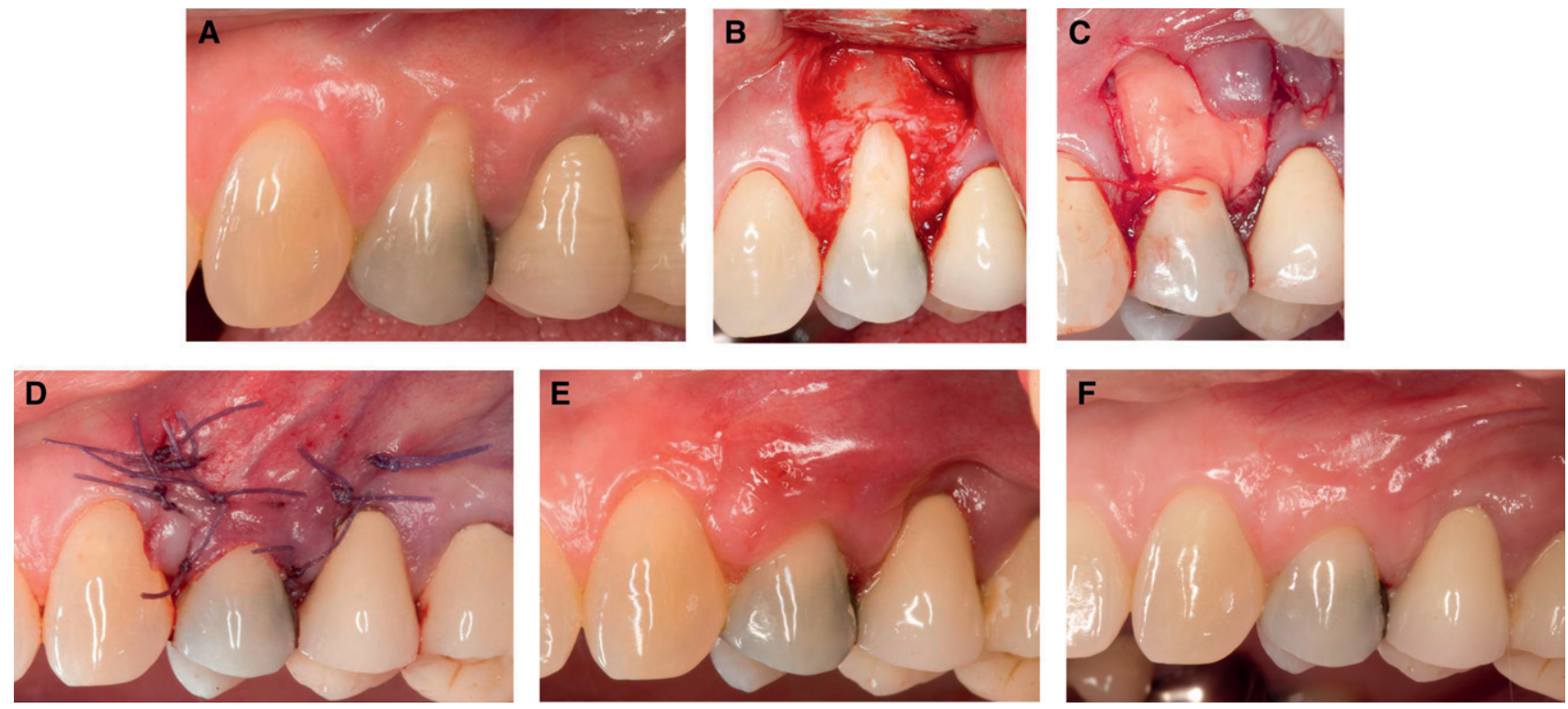

Figure 2.

A patient treated with FDADM. A) Tooth \# I 2 presents 3.5-mm Miller's Class I facial GR. B) The flap was reflected using a full-thickness flap with two divergent vertical releasing incisions. C) FDADM was trimmed to cover at least $3 \mathrm{~mm}$ beyond the recession defect and then secured with single-sling sutures. D) The flap was coronally advanced following the sling-and-tag suturing technique. ${ }^{15}$ E) Four weeks after surgery, there was good soft-tissue healing and recession defect coverage. F) Twelve months after surgery, there was $100 \%$ recession defect coverage.

be questioned. There were no significant differences between groups for CAL, GT, PD, RD, RW, and width of keratinized tissue (KT). Table 3 shows results of the surgeons' questionnaire regarding handling characteristics of the two test materials. There were no statistically significant differences between groups for any parameters except ease of handling, in which SDADM scored higher than FDADM, at $97.4 \%$ and $73.8 \%$, respectively.

When center effect was examined (see supplementary Table 1 in online Journal of Periodontology), all four centers achieved similar clinical outcomes 
Table 2.

\section{Clinical Parameter Changes From Baseline to 12-Month Follow-Up for FDADM and SDADM}

\begin{tabular}{|c|c|c|c|c|}
\hline Variable & $\begin{array}{c}\text { Baseline } \\
(\mathrm{mm} \text {; mean } \pm \mathrm{SD})\end{array}$ & $\begin{array}{c}12 \text { Months } \\
(\mathrm{mm} \text {; mean } \pm \mathrm{SD})\end{array}$ & $\begin{array}{c}\text { Differences } \\
(\mathrm{mm} ; 12 \text { months to baseline) }\end{array}$ & $P$ \\
\hline \multicolumn{5}{|l|}{ CAL } \\
\hline FDADM & $4.04 \pm 0.85$ & $2.34 \pm 1.10$ & $-1.69 \pm 1.08$ & $<0.000$ \\
\hline SDADM & $3.99 \pm 1.04$ & $2.44 \pm 1.22$ & $-1.57 \pm 1.19$ & $<0.000$ \\
\hline \multicolumn{5}{|c|}{ GT I using stent (at $3 \mathrm{~mm}$ apical to the CEI) } \\
\hline FDADM & $0.74 \pm 0.86$ & $1.79 \pm 0.62$ & $0.99 \pm 0.83$ & $<0.000$ \\
\hline SDADM & $1.12 \pm 0.87$ & $1.73 \pm 0.59$ & $0.66 \pm 0.90$ & 0.0001 \\
\hline \multicolumn{5}{|c|}{$\begin{array}{l}\text { GT } 2 \text { using stent (at I mm apical to } \\
\text { the free gingival margin) }\end{array}$} \\
\hline FDADM & $1.21 \pm 0.56$ & $1.72 \pm 0.40$ & $0.50 \pm 0.69$ & $<0.000$ \\
\hline SDADM & $1.30 \pm 0.47$ & $1.58 \pm 0.44$ & $0.32 \pm 0.70$ & 0.0095 \\
\hline \multicolumn{5}{|l|}{ PD distal } \\
\hline FDADM & $2.60 \pm 0.55$ & $2.57 \pm 0.52$ & $-0.04 \pm 0.62$ & 0.6916 \\
\hline SDADM & $2.38 \pm 0.63$ & $2.58 \pm 0.55$ & $0.18 \pm 0.72$ & 0.1407 \\
\hline \multicolumn{5}{|l|}{ PD mesial } \\
\hline FDADM & $2.68 \pm 0.60$ & $2.63 \pm 0.63$ & $-0.04 \pm 0.58$ & 0.6742 \\
\hline SDADM & $2.42 \pm 0.50$ & $2.33 \pm 0.57$ & $-0.11 \pm 0.56$ & 0.2435 \\
\hline \multicolumn{5}{|l|}{ PD mid } \\
\hline FDADM & $1.34 \pm 0.55$ & $1.80 \pm 0.60$ & $0.46 \pm 0.60$ & 0.0002 \\
\hline SDADM & $1.28 \pm 0.49$ & $1.64 \pm 0.54$ & $0.35 \pm 0.56$ & 0.0007 \\
\hline \multicolumn{5}{|l|}{$\mathrm{RD}$} \\
\hline FDADM & $2.73 \pm 0.71$ & $0.72 \pm 1.00$ & $2.00 \pm 0.87$ & $<0.000$ \\
\hline Percentage of root coverage & & & $77.21 \% \pm 29.10 \%$ & \\
\hline SDADM & $2.91 \pm 1.01$ & $0.88 \pm 1.02$ & $2.06 \pm 1.11$ & $<0.000$ \\
\hline Percentage of root coverage & & & $71.01 \% \pm 32.87 \%$ & \\
\hline \multicolumn{5}{|l|}{ RW } \\
\hline FDADM & $3.49 \pm 0.99$ & $1.05 \pm 1.47$ & $-2.51 \pm 1.27$ & $<0.000$ \\
\hline SDADM & $3.47 \pm 0.73$ & $1.40 \pm 1.58$ & $-2.08 \pm 1.56$ & $<0.000$ । \\
\hline \multicolumn{5}{|l|}{ Width of $K T$} \\
\hline FDADM & $3.29 \pm 1.49$ & $3.91 \pm 1.81$ & $0.55 \pm 1.45$ & 0.0256 \\
\hline SDADM & $2.93 \pm 1.76$ & $3.60 \pm 1.65$ & $0.72 \pm 1.07$ & 0.0003 \\
\hline
\end{tabular}

between both groups with two exceptions. Center 3507 achieved significantly greater mesial PD reduction compared to Center 3514, and Center 3508 achieved significantly increased GT compared to Center 3514.

\section{DISCUSSION}

To date, there has been limited published information related to the influence of ADM manufacturing processes on clinical outcomes. ${ }^{11}$ Results from the present study show that there were no differences in clinical outcomes between SDADM and FDADM for root coverage of Miller Class I or II GR defects. Both processed ADM materials achieved significant reduction of RD (average $\approx 2 \mathrm{~mm}$ ) and gained $>70 \%$ root coverage. This is in agreement with a previously published report in which both ADMs were compared in a 6-month study, although Miller Class III recession defects were also included in this study. ${ }^{11}$ In that study, mean recession/percentage coverage were 2.83 $\mathrm{mm} / 81.4 \%$ and $3.13 \mathrm{~mm} / 83.4 \%$ root coverage in SDADM and FDADM, respectively. ${ }^{11}$ Findings from the present study clearly indicated that the outcomes of root coverage in Miller Class I or II recession defects were not related to ADM processing techniques. In addition, the slightly lower percentage of root coverage achieved in the present investigation might be attributable to the surgical approach; an open approach is used which might jeopardize the blood supply and cause another surgical trauma that may induce tissue 


\section{Table 3.}

\section{Comparison of Handling Properties Between FDADM and SDADM}

\begin{tabular}{|c|c|c|c|}
\hline Variable & Value & Statistical Summary & $P$ \\
\hline $\begin{array}{l}\text { How would you rate the ability to handle and } \\
\text { manipulate the hydrated product? (easy, } \\
\text { somewhat difficult, very difficult) }\end{array}$ & & & 0.004 \\
\hline FDADM & Easy & $73.8 \%(31$ of 42$)$ & \\
\hline SDADM & Easy & $97.4 \%$ (37 of 38$)$ & \\
\hline $\begin{array}{l}\text { How did the product adapt to the contours of the } \\
\text { grafted site? (easily adapted, somewhat difficult } \\
\text { to adapt, very difficult to adapt) }\end{array}$ & & & 0.362 \\
\hline FDADM & Easily adapted & $90.5 \%$ (38 of 42$)$ & \\
\hline SDADM & Easily adapted & $97.4 \%$ (37 of 38$)$ & \\
\hline $\begin{array}{l}\text { How would you rate the ability to hydrate the product? } \\
\text { (easy, somewhat difficult, very difficult) }\end{array}$ & & & 0.092 \\
\hline FDADM & Easy & $81.0 \%$ (34 of 42$)$ & \\
\hline SDADM & Easy & $94.7 \%$ (36 of 38$)$ & \\
\hline $\begin{array}{l}\text { Did the edges of the product fray when trimmed? } \\
\text { (yes, no, did not trim) }\end{array}$ & & & 0.092 \\
\hline FDADM & No & $81.0 \%$ (34 of 42$)$ & \\
\hline SDADM & No & $94.7 \%$ (36 of 38$)$ & \\
\hline Did the product remain in place during closure? (yes, no) & & & 0.242 \\
\hline FDADM & Yes & $92.9 \%$ (39 of 42$)$ & \\
\hline SDADM & Yes & $100.0 \%$ (38 of 38$)$ & \\
\hline $\begin{array}{l}\text { Did the product stick to your gloves or instruments } \\
\text { during handling and manipulation? (yes, no) }\end{array}$ & & & 0.117 \\
\hline FDADM & No & $90.5 \%$ (38 of 42$)$ & \\
\hline SDADM & No & $100.0 \%$ (38 of 38) & \\
\hline $\begin{array}{l}\text { Did the product stick to itself during handling and } \\
\text { manipulation? (yes, no) }\end{array}$ & & & 0.242 \\
\hline FDADM & No & $92.9 \%$ (39 of 42$)$ & \\
\hline SDADM & No & $100.0 \%$ (38 of 38$)$ & \\
\hline $\begin{array}{l}\text { If stabilization was necessary, how did the product } \\
\text { respond to sutures? (easily stabilized, slightly } \\
\text { difficult to stabilize, very difficult to stabilize) }\end{array}$ & & & 0.269 \\
\hline FDADM & Easily stabilized & $85.7 \%$ (36 of 42$)$ & \\
\hline SDADM & Easily stabilized & $94.7 \%$ (36 of 38$)$ & \\
\hline $\begin{array}{l}\text { How did the product maintain its structural integrity } \\
\text { during manipulation and handling? (remained } \\
\text { intact, exhibited slight thinning, exhibited } \\
\text { thinning and structural compromise) }\end{array}$ & & & 0.242 \\
\hline FDADM & Intact & $92.9 \%$ (39 of 42$)$ & \\
\hline SDADM & Intact & $100.0 \%(38$ of 38$)$ & \\
\hline
\end{tabular}

Statistical data are presented as \% of total ( $n$ of total).

shrinkage during healing when compared to the tunnel approach. Currently, there is no study comparing the effect of the ADM processing under the tunnel surgical approach. Future research in this area is encouraged. Other factors that may influence current surgical approach outcomes were addressed in several recent systematic reviews. ${ }^{19-21}$ These include, but are not limited to, the following: 1) failure to identify CEJ before surgery; 2) different adjacent papillae dimension; 3 ) different degree of root prominence; 4) full-thickness instead of partial-thickness approach; 5) flap stability; 6) flap mobility; and 7) suturing. When the surgeon failed to control these factors, poor clinical outcomes are often anticipated. ${ }^{19-21}$ 
Data from the present study show that both treatments improved CAL (1.7 mm for FDADM and $1.6 \mathrm{~mm}$ for SDADM), increased tissue thickness at 1 and $3 \mathrm{~mm}$ apical to the free gingival margin (range from 0.3 to $1.0 \mathrm{~mm}$ ), and augmented KT width ( 0.6 to $0.7 \mathrm{~mm}$ ). These results corroborate previous ADM studies ${ }^{15,22-24}$ that showed ADM achieved predictable root coverage and increased GT. Interestingly, a recent systematic review concluded that studies adding ADM under CAF demonstrated a great heterogeneity and no significant benefits compared to CAF alone. ${ }^{21}$ However, they suggested that more studies with longer follow-up are needed to further evaluate the usage of this material under CAF.

It is likely that both ADM materials yielded comparable surgical results because both have a similar collagen matrix structure, which allows easy penetration of new vascular systems into open channels and integration into existing host tissue. ${ }^{25}$ In addition, Cummings et al., 26 in a human histologic study, showed that grafted ADM formed an attachment directly to the root surface through a combination of CT adhesion and long junctional epithelium which, in turn, increased the tissue thickness.

The present study also finds that both KT and PD remained stable during the 12 -month period and that ADM slightly increased the zone of KT, which is in agreement with findings reported previously by Woodyard et al. ${ }^{27}$ The fact that root coverage occurred without PD change with time implied that a new attachment, such as long junctional epithelium and CT attachment, might have been established. It is important to note that the mesial and distal PD were recorded without a custom surgical guide, and this might cause some inconsistent recordings. Nonetheless, the present findings also agree with a recent clinical study by Barker et al. ${ }^{11}$ that showed no difference in root coverage when using SDADM versus FDADM. Both findings are supported by the histologic report that showed that both SDADM- and FDADM-processed materials retained more natural architecture and physical prop-

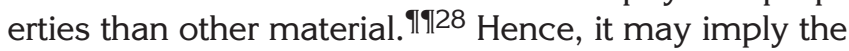
long-term stability of ADM treatment.

In this study, minimal complications are noted in both materials, which implies that ADM, regardless of processing, is a safe material to use in patients. This finding is supported by many previous reports..$^{3-8}$ In this study, the most commonly reported complications are graft exposure and graft infection, with only one case in each treatment group. In the SDADM group, the complication was successfully treated with antibiotics and antimicrobial mouth rinse. In the FDADM group, surgical debridement and revision, antibiotics, and mouth rinse were used to successfully treat the graft exposure and infection. Healing with ADM begins with preserved proteoglycans and proteins di- recting the patient's own cells to initiate revascularization and cell repopulation. Significant revascularization is observed after 7 to 10 days as fibroblasts begin tissue remodeling. ${ }^{29}$ At 45 days, CT forms through host collagen deposition and the ADM is repopulated with cells and remodels during the next 3 to 6 months. ${ }^{29}$ If the ADM is left exposed, as in the case of free gingival grafting, the ADM matrix will support epithelial cell migration. ${ }^{28}$ Although the complication incidence was low, it is important to recognize these possible complications and learn how to deal with them properly. In addition, both materials handle almost identically, except SDADM showed better ease-of-handling characteristics than FDADM. This might be because the SDADM processing preserves the original dermis structure, and, by using chemical agents to dehydrate the material, it eliminates the need for preserving the material in antibiotic solution under freeze-dried conditions. As a result, no dual hydration/dilution is needed before the clinical usage. As the result, no defreezing is needed before the clinical usage. This is somewhat supported by the study published by Hinton et al., ${ }^{30}$ who demonstrated that SDADM-processed fascia lata works better as a grafting material than FDADM obtained from tissue banks. Nonetheless, it has to be cautioned that fascia lata is not the same material as dermis, although the same material processing techniques were used.

Interestingly, results from this study show that there was no difference among the four centers. This suggested that, by adhering to the surgical protocol, clinical outcomes were predictable, no matter who the operator. Nonetheless, to ensure that the proper surgical technique was used among centers, prestudy training was conducted to ensure that similar surgical approaches were performed. This might explain why there was no center effect.

\section{CONCLUSIONS}

Within the limitations of this study, both FDADM and SDADM can be successfully used to correct Miller Class I or II recession defects with equivalent outcomes. There were no statistically significant differences among groups for any of the clinical parameters tested.

\section{ACKNOWLEDGMENTS}

Drs. Romanos, Geurs, and Sullivan contributed equally to this project. The study is supported by a grant from Zimmer Dental. Dr. Romanos received honorarium for speaking engagements with Zimmer Dental. Dr. Wang received honorarium for speaking engagements with BioHorizons. Zimmer Dental reimbursed Dr. Eber for hotel expenses to present data related to this study at the American Association for

Iๆ DuraDerm Collagensis, Beverly, MA 
Dental Research annual meeting. The authors thank Dr. Hai-Bo Wen, Ms. Kim Bradbury, and Mr. Michael Collins (all employees of Zimmer Dental) for their assistance in conducting this research and preparing this manuscript. Also, the authors thank all personnel, from each study center, who participated in this multicenter study.

\section{REFERENCES}

1. Albandar JM, Kingman A. Gingival recession, gingival bleeding, and dental calculus in adults 30 years of age and older in the United States, 1988-1994. JPeriodontol 1999;70:30-43.

2. Litonjua LA, Andreana S, Bush PJ, Cohen RE. Toothbrushing and gingival recession. Int Dent $J$ 2003;53: 67-72.

3. Chavan RS, Bhongade ML, Tiwari IR, Jaiswal P. Open flap debridement in combination with acellular dermal matrix allograft for the prevention of postsurgical gingival recession: A case series. Int $J$ Periodontics Restorative Dent 2013;33:217-221.

4. Koudale SB, Charde PA, Bhongade ML. A comparative clinical evaluation of acellular dermal matrix allograft and sub-epithelial connective tissue graft for the treatment of multiple gingival recessions. J Indian Soc Periodontol 2012;16:411-416.

5. Kuis D, Sciran I, Lajnert V, et al. Coronally advanced flap alone or with connective tissue graft in the treatment of single gingival recession defects: A long-term randomized clinical trial. J Periodontol 2013;84:1576-1585.

6. Ahmedbeyli C, Ipçi SD, Cakar G, Kuru BE, Yılmaz S. Clinical evaluation of coronally advanced flap with or without acellular dermal matrix graft on complete defect coverage for the treatment of multiple gingival recessions with thin tissue biotype. J Clin Periodontol 2014;41:303-310.

7. Thomas LJ, Emmadi P, Thyagarajan R, Namasivayam A. A comparative clinical study of the efficacy of subepithelial connective tissue graft and acellular dermal matrix graft in root coverage: 6-month follow-up observation. $J$ Indian Soc Periodontol 2013;17:478-483.

8. de Souza SL, Novaes AB Jr, Grisi DC, Taba M Jr, Grisi MF, de Andrade PF. Comparative clinical study of a subepithelial connective tissue graft and acellular dermal matrix graft for the treatment of gingival recessions: Six- to 12-month changes. J Int Acad Periodontol 2008; 10:87-94.

9. Gapski R, Parks CA, Wang HL. Acellular dermal matrix for mucogingival surgery: A meta-analysis. J Periodontol 2005;76:1814-1822.

10. Schöepf C. Allograft safety: The efficacy of the tutoplast process. Int Magazine Oral Implant 2006; 1:10-15.

11. Barker TS, Cueva MA, Rivera-Hidalgo F, et al. A comparative study of root coverage using two different acellular dermal matrix products. J Periodontol 2010; 81:1596-1603.

12. Miller PD Jr. A classification of marginal tissue recession. Int J Periodontics Restorative Dent 1985;5:8-13.

13. Novaes AB Jr, Grisi DC, Molina GO, Souza SL, Taba M Jr, Grisi MF. Comparative 6-month clinical study of a subepithelial connective tissue graft and acellular dermal matrix graft for the treatment of gingival recession. J Periodontol 2001;72:1477-1484.

14. O'Leary TJ, Drake RB, Naylor JE. The plaque control record. J Periodontol 1972;43:38.
15. Huang LH, Wang HL. Sling and tag suturing technique for coronally advanced flap. Int J Periodontics Restorative Dent 2007;27:379-385.

16. Silness J, Loe H. Periodontal disease in pregnancy. II. Correlation between oral hygiene and periodontal condtion. Acta Odontol Scand 1964;22:121-135.

17. Löe $H$. The gingival index, the plaque index and the retention index systems. J Periodontol 1967;38(Suppl. 6):610-616.

18. Huang LH, Neiva RE, Wang HL. Factors affecting the outcomes of coronally advanced flap root coverage procedure. J Periodontol 2005;76:1729-1734.

19. de Sanctis M, Clementini M. Flap approaches in plastic periodontal and implant surgery: Critical elements in design and execution. J Clin Periodontol 2014;41 (Suppl. 15):S108-S122.

20. Zuhr O, Bäumer D, Hürzeler $M$. The addition of soft tissue replacement grafts in plastic periodontal and implant surgery: Critical elements in design and execution. J Clin Periodontol 2014;41(Suppl. 15):S123-S142.

21. Cairo F, Nieri M, Pagliaro U. Efficacy of periodontal plastic surgery procedures in the treatment of localized facial gingival recessions. A systematic review. J Clin Periodontol 2014;41(Suppl. 15):S44-S62.

22. Harris RJ. A comparative study of root coverage obtained with an acellular dermal matrix versus a connective tissue graft: Results of 107 recession defects in 50 consecutively treated patients. Int $J$ Periodontics Restorative Dent 2000;20:51-59.

23. Paolantonio M, Dolci M, Esposito P, et al. Subpedicle acellular dermal matrix graft and autogenous connective tissue graft in the treatment of gingival recessions: A comparative 1-year clinical study. J Periodontol 2002;73:1299-1307.

24. Henderson RD, Greenwell H, Drisko C, et al. Predictable multiple site root coverage using an acellular dermal matrix allograft. J Periodontol 2001;72:571-582.

25. Yukna RA, Tow HD, Caroll PB, Vernino AR, Bright RW. Comparative clinical evaluation of freeze-dried skin allografts and autogenous gingival grafts in humans. $J$ Clin Periodontol 1977;4:191-199.

26. Cummings LC, Kaldahl WB, Allen EP. Histologic evaluation of autogenous connective tissue and acellular dermal matrix grafts in humans. J Periodontol 2005;76:178-186.

27. Woodyard JG, Greenwell H, Hill M, Drisko C, lasella JM, Scheetz J. The clinical effect of acellular dermal matrix on gingival thickness and root coverage compared to coronally positioned flap alone. J Periodontol 2004;75:44-56.

28. Sclafani AP, McCormick SA, Cocker R. Biophysical and microscopic analysis of homologous dermal and fascial materials for facial aesthetic and reconstructive uses. Arch Facial Plast Surg 2002;4:164-171.

29. Buinewicz B, Rosen B. Acellular cadaveric dermis (AlloDerm): A new alternative for abdominal hernia repair. Ann Plast Surg 2004;52:188-194.

30. Hinton R, Jinnah RH, Johnson C, Warden K, Clarke HJ. A biomechanical analysis of solvent-dehydrated and freeze-dried human fascia lata allografts. A preliminary report. Am J Sports Med 1992;20:607-612.

Correspondence: Dr. Hom-Lay Wang, 1011 N. University Ave., Ann Arbor, MI 48109-1078. Fax: 734/936-0374; e-mail: homlay@umich.edu.

Submitted April 9, 2014; accepted for publication June $10,2014$. 